\title{
When names are less than crystal clear
}

Sir - The problems of naming biological objects, such as genes, have been aired in Nature several times. Some of us, for example Drosophila geneticists, have been criticized for what has been seen as a "whimsical" attitude to gene names ${ }^{1}$.

But there is now another problem. You published a Letter ${ }^{2}$ by Kreusch et al. about the structure of the tetramerization domain of the Shaker potassium channel. Shaker is the "whimsical" name of a Drosophila gene that encodes a potassium channel, and was so called because mutant flies shake under etherization. It was, I believe, the first potassium-channel gene to be cloned.

In fields other than Drosophila genetics, the name Shaker is used to describe a family of potassium-channel proteins. All of your readers will (I hope) have several genes in their genome encoding proteins of this, and the related Shab, Shaw and Shal families. I have read every word of Kreusch et al. ${ }^{2}$ in the hope of learning which species donated its gene for this (undoubtedly fine) study. Is it the Drosophila melanogaster Shaker protein? One of the human ones? Or perhaps from the lesser-eared bat, endemic to the lower caves on Mt Elgon in western Kenya? I have looked in the Protein Data Bank, only to find that the record is still being processed.

Do crystallographers have no concern for the variety of life? Have they no sympathy for those of us who are trying to build even bigger and better databases for biologists (I work on Flybase, a Drosophila database)? Are Nature's word limits so

\section{Tokyo campus rising}

Sir - While appreciating your interest in the University of Tokyo's plan for a new campus and the research departments that will occupy a central role in it, I would like to take issue with several comments in your coverage (Nature 392, 429; \& 393, 5; 1998).

First, in response to your statements that we have had difficulty in obtaining the land for the Kashiwa campus, I would like to point out that this was partially acquired in 1995, and construction of the Institute of Solid State Physics is already under way. Land for the new research departments was purchased in April of this year through the government's supplementary budget.

Second, you argue that the commitment of funds to the new research departments has adversely affected the redevelopment of existing departments and institutes. Although there is a university-wide consensus on giving high priority to the new departments, we are also reviewing the priorities for the redevelopment of the severe that a subeditor struck out the organism's name? Or do crystallographers simply not care? Whatever the answer, it is all very frustrating and, worse, bad practice. Michael Ashburner

Department of Genetics, University of Cambridge, Cambridge CB2 3EH, UK

Senyon Choe and Paul Pfaffinger replyOur primary concern in reporting any scientific finding is to be accurate and precise. In a Letter to Nature, there is the additional requirement of brevity, while making findings accessible to a general scientific readership. Regarding the source of the Shaker protein, we erred on the side of accuracy, precision and brevity, but lost a general scientific reader, such as Ashburner. The protein source was identified at several points in our Letter ${ }^{1}$ as the $\mathrm{AK}_{\mathrm{v}} 1.1 \mathrm{a}$ Shakertype potassium channel, and a reference to the first use of this name in the literature was provided. A query of NCBI GenBank with the name $\mathrm{AK}_{\mathrm{v}} 1.1 \mathrm{a}$ correctly identifies the Aplysia californica channel sequence, and provides a page of further information.

A complete entry for our crystal structure was supplied to the Protein Data Bank, who were instructed to release this information upon publication. We believe that scientific advance thrives on openness, and we have an obligation to make available our material and data once published.

Finally, the use of the Shaker name to identify the channel subfamily, rather than a specific gene from Drosophila, is perhaps an

existing departments and institutes. Some of the redevelopment projects — such as the recently completed construction of the Faculty of Science Research Tower, the redevelopment of the Komaba campus, and the construction of a medical school building — are already becoming a reality.

Finally, you comment on the question of age limits for faculty members recruited to the new research departments. Although it was indicated that promising young scholars were being sought for certain associate professor positions, such an age limit is not a requirement in all fields.

Every effort is being made to ensure that the successful setting up of the departments is a goal of the entire university community, and we believe firmly that they represent a welcome change from the present rigid structure of graduate education and research in Japan. The new research departments were inaugurated in April. Shun-ichi Kobayashi (Vice-President) University of Tokyo, 7-3-1 Hongo, Bunkyo-ku, Tokyo 113-8654, Japan important topic for further discussion. Because we entered into this problem from the viewpoint of trying to understand how the ordered assembly of potassium-channel subunits is restricted to heteromultimerization with other proteins in the same subfamily, we see the importance of the Shaker subfamily name. Indeed, from our viewpoint it is remarkable that Shaker subfamily members selectively heteromultimerize across species, from Aplysia to human, and probably even elephants and lesser-eared bats (although the molecular biology of ion channels in the latter species has been woefully neglected).

We have produced a comparative analysis of the structural conservation of the $\mathrm{T} 1$ domain region for all 55 sequences that we could clearly identify in the gene database as Shaker members, as implicitly provided in Fig. $3 \mathrm{~b}$ of the Letter ${ }^{2}$. The complete alignment is accessible at: http://sbl.salk.edu/ choe/clustal.html. We hope to provide further information about this topic, and other implications of our research on the T1 domain, for both Shaker and non-Shaker channels, in future reports. Senyon Choe

Structural Biology Laboratory, The Salk Institute,

La Jolla, California 92037, USA

\section{Paul Pfaffinger}

Division of Neuroscience, Baylor College of Medicine, Houston, Texas 77030, USA 1. Jan, Y. N. Nature 389, 665 (1997).
2. Kreusch, A., Pfaffinger, P. J., Stevens, C. F. \& Choe, S. Nature 392,
945-948 (1998).

\section{Haldane's speculation}

Sir - The retrospective review, by David Jones, of The Scientist Speculates says "how they kept J. B. S. Haldane out of it [the book] remains a mystery" (Nature 393, $642 ; 1998)$. I am writing to resolve that mystery.

A nice article by Haldane was accepted, but he was annoyed when the publishers put out an advance leaflet in which Arthur Koestler was put at the head of a list of scientific contributors. Haldane regarded that as inappropriate and withdrew his article. It was published later in Science News (Penguin).

On another point, my guess in 1962 for the cost of reaching full artificial intelligence by 1978 was $\$ 10^{8.7 \pm 1}$, so the $95 \%$ interval was from $\$ 5$ million to $\$ 50$ billion. This guess was not refuted! I. J. Good

Department of Statistics,

Virginia Polytechnic Institute and State University, Blacksburg, Virginia 24061-0439, USA 